\title{
Cervantes y la corte: La española inglesa y la lógica del servicio-merced*
}

\author{
Blanca Santos De la Morena** \\ MANUEL PiQueras FlORES***
}

\begin{abstract}
Resumen
En este artículo estudiamos la aparición de la corte de Elisabeth I de Inglaterra en La española inglesa, de Cervantes. En primer lugar, repasamos brevemente las relaciones de Cervantes con el sistema cortesano y las ideas principales sobre la corte que se contienen en su obra. A continuación, mostramos cómo se representa en esta novela la lógica del servicio-merced. Mientras que todos los personajes ingleses pertenecen a la alta nobleza, los padres de Isabela, por su condición de burgueses, son ajenos a la cultura cortesana. La pareja protagonista, que en Londres está sujeta al servicio a la reina de Inglaterra y depende de sus mercedes, solo puede desarrollar su amor de una manera libre cuando se reúne en Sevilla y el personaje masculino renuncia a su nobleza y se inserta en el linaje burgués de su esposa.
\end{abstract}

Palabras clave: corte; servicio-merced; nobleza; burguesía; libertad; Cervantes.

Title: Cervantes and the Court: La española inglesa and the Logic of Service-Mercy

\begin{abstract}
In this paper we study the portrait of the Elizabeth I's court in La española inglesa by Cervantes. First of all, we review briefly the relationship between Cervantes and the courtier system, as well as the principal ideas about the court in his work. Secondly, we show how the logic of service-mercy is depicted in this novel. While every English character belongs to the high nobility, the parents of Isabela, who come from bourgeoisie, are foreign to the courtier culture. In London, the protagonist couple must serve the queen and

* Este trabajo ha sido financiado por la Fundación Alexander von Humboldt gracias a sendas becas postdoctorales Humboldt, desarrolladas en la Westfälische Wilhelms-Universität Münster (Blanca Santos de la Morena) y en la Rheinische Friedrich-Wilhelms-Universität Bonn (Manuel Piqueras Flores).

** Westfälische Wilhelms-Universität Münster. blanca.santos1710@gmail.com / ORCID iD: https://orcid.org/0000-0001-7336-9587

*** Universidad de Jaén. manuel.piqueras@ujaen.es / ORCID iD: https://orcid.org/0000-00020109-1704
\end{abstract}


depends on her mercies. They can only develop their love relationship freely when they meet in Seville and the male character renounces his nobility, and he chooses the bourgeois class of his wife.

Keywords: Court; Service-Mercy; Nobility; Bourgeoisie; Freedom; Cervantes.

\section{Cómo citar este artículo / Citation}

Santos de la Morena, Blanca y Manuel Piqueras Flores. 2021. «Cervantes y la corte: La española inglesa y la lógica del servicio-merced». Anales Cervantinos 53: 221-237. https://doi.org/10.3989/anacervantinos.2021.009

En los últimos años, las investigaciones que han relacionado el cultivo de la literatura del Siglo de Oro español con el modelo de vida cortesano han experimentado un notable desarrollo fruto de la profundización en los estudios sobre la corte y el llamado «discurso cortesano», tal y como lo ha definido Amedeo Quondam; un fenómeno «que afectó no solo al orden político, sino también a la organización social y a los cambios de mentalidad y comportamiento en Occidente» (Torres Corominas 2013, 10) ${ }^{1}$. De esta manera, al hablar de la corte no solamente nos estamos refiriendo a un sistema de ordenación política sino también a un modo de vida que en la España de los siglos XVI y XVII -como en el resto de Europa- permeó en toda la cultura escrita, más allá de los géneros literarios estrictamente relacionados con la nobleza o el palacio. Como indica Marín Cepeda $(2015,12)$ :

Conocida es [...] la importancia que la cultura escrita adquirió para la nobleza cortesana, de manera que los escritores del Siglo de Oro no pudieron sustraerse a las relaciones de clientelismo y patronazgo de sus protectores o mecenas [...]. Conviene asumir que la práctica literaria comportó en el Siglo de Oro una serie de tomas de posición, relacionadas con las aspiraciones literarias, políticas o sociales del escritor, que necesariamente hubieron de hallar su caja de resonancia en el texto literario.

De esta manera, ni siquiera el éxito de un escritor de masas como Lope de Vega, que le permitió alcanzar el primer estado de protoprofesionalización de la Edad Moderna (García Reidy 2013, 399), pudo liberarle «de sus obligaciones clientelares dentro del sistema predominante de mecenazgo» (Gómez $2013,37)^{2}$.

1. Sobre la sociedad cortesana, véase, además, el fundamental estudio de Elias (2017). Sobre el concepto de corte en la Monarquía Hispánica resultan esenciales los estudios del Instituto Universitario la Corte en Europa. Como punto de partida, especialmente para el contexto histórico cervantino, cabe consultar Martínez Millán (1994).

2. El Fénix de los ingenios desarrolló su trayectoria literaria con «una conciencia autorial en tensión, entre el orgullo de la obra creada para el mercado literario y el ansia por pertenecer a una idealizada concepción aristocrática de la literatura, plasmada a través de la búsqueda de mecenazgo nobiliario y regio» (García Reidy 2013, 15-16). Véase al respecto también Gutiérrez Valencia, Cristina (2019, 
En este sentido, por su centralidad dentro del canon así como por la evolución de su trayectoria literaria y de su proyección autorial, el caso de Miguel de Cervantes resulta especialmente significativo ${ }^{3}$. Los primeros versos del autor están directamente conectados con la producción de una literatura para la corte a través del personaje de la reina Isabel de Valois. A ella dedicó un soneto con motivo del nacimiento de la segunda hija de los soberanos, Micaela Catalina, en 1567, y poco más tarde compuso varios poemas para la Historia y relación verdadera de la enfermedad, felicísimo tránsito y sumptuosas exequias fúnebres de la Serenísima Reina de España Doña Isabel de Valois (Madrid, Pierres Cosin, 1569): un epitafio en forma de soneto, dos poemas en redondillas y una elegía en tercetos ${ }^{4}$. El volumen fúnebre, patrocinado por la Villa de Madrid (Alvar Ezquerra 2014, 317), fue editado por Juan López de Hoyos, el director del Estudio de la Villa, quien se refiere en él al joven Miguel como «nuestro amado y caro discípulo» (f. $147 \mathrm{v}$ ), lo que ha servido para conjeturar sobre la posible formación del complutense. El poema más significativo de los que compuso el autor del Quijote en este volumen es la elegía -dedicada al Cardenal Diego de Espinosa- que, como indica Rey Hazas, supone «la primera manifestación cervantina de búsqueda de favor» $(2005,17)$. Según reza el título, se trata de un texto escrito «en nombre de todo el Estudio» (López de Hoyos 1569 , f. $157 \mathrm{v})$, lo que ha hecho suponer que «debió ser su maestro [...] quien sugiriera su escritura, sabedor de que el cardenal Espinosa era, por aquellas fechas, el hombre más poderoso de España» (Rey Hazas 2005, 17). Al respecto, recuerda Teijeiro Fuentes $(2013,11)$ que el cardenal había protegido a López de Hoyos y lo había promovido como director del Estudio. Los versos cervantinos suponen un claro elogio, en los que «la imprescindible figura de Espinosa alcanza una trascendencia política que le obliga en estos dolorosos momentos a tomar el timón del gobierno y guiar al rebaño con su virtud» (Teijeiro Fuentes 2013, 11). Hay en ellos una intención de posicionarse como partidario de Espinosa, cuya figura «rompía el sistema bipartidista de relaciones de poder que venía rigiendo en la corte desde el inicio» (Marín Cepeda 2007, 4). Por esas fechas, el cardenal construía su propia red clientelar con figuras como Juan de Ovando y su secretario, un jovencísimo Mateo Vázquez, ambos relacionados con la biografía cervantina ${ }^{5}$.

134-217): Procesos de configuración autorial en el Siglo de Oro: el caso de Lope de Vega. Universidad de Oviedo, tesis doctoral, así como la reciente biografía de Sánchez Jiménez (2018). Sobre la figura del autor literario en el Siglo de Oro español cabe consultar los trabajos colectivos coordinados por Tietz y Trambaioli (2011), Montero y Sánchez Jiménez (2017) y Ruiz (2019a).

3. Sobre la particular posición de Cervantes en el campo literario de su época y su participación en las incipientes dinámicas de profesionalización, véanse los recientes trabajos de Ruiz $(2018,179$ 192; 2019b).

4. Véanse al respecto las páginas dedicadas por Sáez $(2016,22-23)$ en su edición de la poesía cervantina.

5. Juan de Ovando, nombrado presidente del Consejo de Indias por Espinosa (1571-1574) y más tarde presidente del consejo de Hacienda (1574-1575), era familiar directo -tío (Teijeiro 2013, 12; Canavaggio 2005, 46), primo (Lucía Megías 2016a) o hermano (Sliwa 2005, 739)- de Nicolás de Ovando, que tuvo una hija con Andrea de Cervantes, la hermana del escritor, llamada Constanza. 
Una década más tarde, en la Epístola que Cervantes dirige al entonces poderoso secretario de Felipe II, el escritor se refiere a los diez años que ha servido al monarca: «Diez años ha que mudo y tiendo el paso / en servicio del gran Filipo nuestro» (Cervantes 2016, vv. 106-107). Lo mismo se indica, según Lucía Megías (2016a), en la Información de limpieza de sangre de 1578. Durante esa década Cervantes ha tenido una vida tumultuosa. Primero aparece en Roma, como camarero del futuro cardenal Giulio Acquaviva, cargo que abandona antes de que su señor obtenga el capelo cardenalicio. Según Canavaggio $(2005,81)$, esta fue una experiencia que debió dejarle recuerdo de las intrigas cortesanas del Vaticano. Después, como es sabido, ejerce como soldado en las campañas del Mediterráneo. A su vuelta a España, la galera en la que viaja es apresada por los piratas turcos y debe enfrentarse a cinco años de cautiverio.

Antes de ser capturado, el soldado Cervantes volvía a España para procurarse un lugar en la corte, «para que su majestad le hiciese merced» (Lucía Megías 2016b), como consta en el extracto de uno de los memoriales posteriores. Es lo que intentará también tras su liberación, buscando un cargo para el que probablemente había orientado su formación, como parece indicar el hecho de que escribiera con bastarda canónica, la letra propia de escribanos (Lucía Megías 2016a). Especialmente conocidos son sus intentos por buscar una nueva vida en el Nuevo Mundo, de los que queda constancia autógrafa en su carta a Antonio de Eraso (Montero Reguera 1992, 94). La madurez del complutense está ligada a la vida cortesana, como ha resaltado también Lucía Megías $(2016 b)^{6}$ : «Siempre se mantuvo en el cerco de la corte hispánica a la espera de su merced» ${ }^{7}$. Esta actividad se refleja también en su escritura, como muestra la dedicatoria de La Galatea (1585), dirigida a Ascanio Colonna, o el soneto laudatorio que escribe para la Filosofía cortesana de Alonso de Barros (1588). Sus posiciones en la corte durante esta época «han recibido hipótesis contrapuestas» (Marín Cepeda 2016, 34), aunque «se observan movimientos de aproximación a los grupos que gozaban de la preeminencia política de cada período» $(2016,34)$. Como es sabido, Cervantes no consiguió una verdadera merced, un puesto como secretario o cronista que solventara sus necesidades económicas, sino encargos puntuales que conllevaron notables infortunios, como la excomunión o la cárcel. Sin embargo, todavía en 1605, en las declaraciones fruto de las averiguaciones del llamado Caso Ezpeleta, su hermana Andrea indica que su hermano es un «hombre que escribe e trata de negocios, e que por su buena habilidad tiene amigos» (Canavaggio 1997, 34), por lo que se ha supuesto que quizá Cervantes se desenvolviera como agente de negocios (Lucía Megías 2016b).

Nicolás dio su apellido a la niña, pero rompió su promesa de matrimonio con Andrea, pagándole una compensación económica.

6. El estudioso ha subtitulado precisamente la parte de su biografía dedicada a la madurez de Cervantes «Una vida en la corte».

7. Véase al respecto, además de las biografías citadas, Alvar Ezquerra (2004, 179, 254-259), García López (2015, 105-145) y Gracia (2016, 147-193). 
En general, existe acuerdo crítico en torno a un creciente desencanto por parte del escritor alcalaíno con el mundo cortesano, que se acentúa en los últimos años de su vida, en los que se dedica con mayor intensidad a la escritura, reescritura y publicación de sus obras, probablemente en gran medida para paliar la situación económica de su familia. La última merced que no le es concedida es la de acompañar a Nápoles al recién nombrado virrey, el conde de Lemos, situación a la que alude en el Viaje del Parnaso ${ }^{8}$, precisamente la única obra que, desde 1613, no dirige al noble ${ }^{9}$. Este poema, la obra más autobiográfica de Cervantes (Canavaggio 1981), se abre con una mención a su modelo literario, el Viaggo di Parnaso de Cesari Caporali, de quien se dice que «le vino en voluntad de ir a Parnaso, / por huir de la corte el vario estruendo» $\left(2016\right.$, I, vv. 5-6) ${ }^{10}$. Eso es lo que precisamente, a partir de 1604, parecen hacer los personajes de Cervantes en sus obras mayores. En el Quijote encontramos una oposición de la figura del caballero andante con la del cortesano, que se hace explícita en los capítulos iniciales de la segunda parte: en el quinto se desarrolla un diálogo de Sancho con su mujer, en el que Teresa Panza defiende y alaba la vida fuera de la corte ${ }^{11}$, mientras que en el sexto don Quijote establece, a partir de una pregunta del ama, las diferencias

8. Cervantes, como es sabido, culpa a los hermanos Argensola -Lupercio era el secretario del conde- de la decisión: «Mandome el del alígero calzado / que me aprestase y fuese luego a tierra / a dar a los Lupercios un recado, / en que les diese cuenta de la guerra / temida, y que a venir les persuadiese / duro y fiero asalto, al ¡cierra, cierra! / "Señor", le respondí, "si acaso hubiese / otro que la embajada les llevase, / que más grato a los dos hermanos fuese / que yo no soy, sé bien que negociase / mejor". Dijo Mercurio: "No te entiendo, / y has de ir antes que el tiempo más se pase". "Que no me han de escuchar estoy temiendo", / le repliqué; "y así, el ir yo no importa, / puesto que en todo obedecer pretendo. / Que no sé quién me dice y quién me exhorta / que tienen para mí, a lo que imagino / la voluntad, como la vista, corta. / Que si esto así no fuera, este camino / con tan pobre recámara no hiciera, / ni diera en un tan hondo desatino. / Pues si alguna promesa se cumpliera / de aquellas muchas que al partir me hicieron, / lléveme Dios si entrara en tu galera. / Mucho esperé, si mucho prometieron, / mas podía ser que ocupaciones nuevas / les obligue a olvidar lo que dijeron. / Muchos, señor, en la galera llevas / que te podrán sacar el pie del lodo: / parte, y escusa de hacer más pruebas". "Ninguno", dijo, "me hable dese modo, / que si me desembarco y los embisto, / voto a Dios, que me traiga al Conde y todo. Con estos dos famosos me enemisto..."» (2016, III, vv. 163-196).

9. Las dedicatorias constituían una herramienta básica para situarse dentro del campo literario e intentar obtener algún mecenazgo, y por ello mismo estaban sujetas a unos moldes retóricos establecidos. Cervantes, sin embargo, en las suyas «irá adelgazando [...] la laudatio hipertrofiada y convencional» (Marín Cepeda 2016, 39).

10. Varias de las referencias que siguen a continuación, sobre el mundo de la corte desde una perspectiva negativa en la obra cervantina, han sido señaladas por Marín Cepeda (2016, 40-41).

11. «-Medíos, Sancho, con vuestro estado -respondió Teresa-, no os queráis alzar a mayores y advertid al refrán que dice: «Al hijo de tu vecino, límpiale las narices y métele en tu casa». ¡Por cierto que sería gentil cosa casar a nuestra María con un condazo, o con caballerote que cuando se le antojase la pusiese como nueva, llamándola de villana, hija del destripaterrones y de la pelarruecas! i[...] temo que este condado de mi hija ha de ser su perdición. Vos haced lo que quisiéredes, ora la hagáis duquesa o princesa, pero séos decir que no será ello con voluntad ni consentimiento mío. Siempre, hermano, fui amiga de la igualdad, y no puedo ver entonos sin fundamentos. "Teresa" me pusieron en el bautismo, nombre mondo y escueto, sin añadiduras ni cortapisas, ni arrequives de dones ni donas; 'Cascajo' se llamó mi padre; y a mí, por ser vuestra mujer, me llaman "Teresa Panza" (que a buena razón me habían de llamar "Teresa Cascajo", pero allá van reyes do quieren leyes), y con este nombre me contento» (Cervantes 2015, 726-728). 
entre cortesanía y caballería ${ }^{12}$. Los protagonistas de la novela no pisan Madrid, omisión que se debe, según Rey Hazas «a su rechazo, no como ciudad, sino como sede de la corte de los Austrias, esto es, como centro de un poder absoluto en el que no existía margen para la libertad y donde imperaba el todopoderoso caballero quevedesco don Dinero», y que «era además el mejor ejemplo de la injusticia» (Rey Hazas 2013, 195). Por ello, en la primera parte Cervantes construiría en la venta de Juan Palomeque el Zurdo «una síntesis perfecta de la sociedad seiscentista española, o, si se quiere, a su enseña y símbolo: la Corte [...], para burlarse de ella, de su necia vaciedad, de su vana inconsistencia, de la superficialidad de sus intereses y preocupaciones») (2013, 196-197). En la segunda parte, de manera estructuralmente paralela, la acción no se detiene ya en una venta, sino en el palacio de los duques: ahora la crítica es más afilada y apunta directamente a una nobleza ociosa (Piqueras Flores y Trapanese 2020, 241-243) que ha carnavalizado la corte (Redondo 1998). Una muestra de las connotaciones anticortesanas con las que fue leída la inmortal novela es que, según indica Crespo, la publicación del Quijote de Avellaneda (1614) puede entenderse como «réplica señorial al intencionado 'desencantamiento' del Quijote cervantino, una recuperación del sentido y poder áulicos de quien conoce bien la Corte» (2002, 294-295).

Significativa es también la ausencia de Madrid en Los trabajos de Persiles y Sigismunda, ciudad que los protagonistas de la novela y su nutrida compañía evitan por las siguientes razones:

Tampoco quisieron pasar por Madrid, donde a la sazón estaba la corte, temiendo algún estorbo que su camino les impidiese. Confirmoles en este parecer la antigua peregrina, diciéndoles que andaban en la corte ciertos pequeños, que tenían fama de ser hijos de grandes; que, aunque pájaros noveles, se abatían al señuelo de cualquiera mujer hermosa, de cualquiera calidad que fuese: que el amor antojadizo no busca calidades, sino hermosura (Cervantes 2017, III, VIII, 291).

Las Novelas ejemplares, en cambio, comienzan en Madrid con La Gitanilla y concluyen en Valladolid con El coloquio de los perros. Es decir, las dos sedes de la Monarquía hispánica -Valladolid lo fue entre 1601 y 1606-abren y cierran espacialmente la colección. La Gitanilla contiene varias alusiones negativas a la vida en la corte, tanto en sus aspectos sociales como en los políticos. Como en el Persiles, Madrid aparece como una ciudad peligrosa para las jóvenes, en este caso para las labradoras y las gitanas:

12. «-Mira, amiga -respondió don Quijote-, no todos los caballeros pueden ser cortesanos, ni todos los cortesanos pueden ni deben ser caballeros andantes: de todos ha de haber en el mundo, y aunque todos seamos caballeros, va mucha diferencia de los unos a los otros; porque los cortesanos, sin salir de sus aposentos ni de los umbrales de la corte, se pasean por todo el mundo mirando un mapa, sin costarles blanca, ni padecer calor ni frío, hambre ni sed; pero nosotros, los caballeros andantes verdaderos, al sol, al frío, al aire, a las inclemencias del cielo, de noche y de día, a pie y a caballo, medimos toda la tierra con nuestros mismos pies, y no solamente conocemos los enemigos pintados, sino en su mismo ser» $(2015,733)$. 
Fuéronse, y juntáronse con las muchas labradoras que a la hora de las avemarías suelen salir de Madrid para volverse a sus aldeas, y entre otras vuelven muchas, con quien siempre se acompañaban las gitanas y volvían seguras; porque la gitana vieja vivía en continuo temor, no le salteasen a su Preciosa (Cervantes 2013, 51-52).

Así, se entiende que don Juan/Andrés pida a su enamorada que no visite la ciudad hasta que emprendan su viaje: «Que no vayas más a Madrid; porque no querría que algunas de las demasiadas ocasiones que allí pueden ofrecerse me salteasen la buena ventura que tanto me cuesta» $(2013,59)$, algo a lo que se niega la gitana. El joven caballero no tiene problema en abandonar la corte y perseguir el amor de Preciosa, en un mundo rural y nómada que idealiza la vida de los gitanos a través de moldes pastoriles. En La Gitanilla, la corte es el ámbito de la corrupción, tal y como indica Preciosa al honrado teniente: «Coheche vuesa merced, señor tiniente, coheche y tendrá dineros $[\ldots]$, por ahí he oído decir $[\ldots]$ que de los oficios se ha de sacar dineros para pagar las condenaciones de las residencias, y para pretender otros cargos» $(2013,50)$; la muchacha, además, añade: «En algunos palacios más medran los truhanes que los discretos» $(2013,51)$. Justamente, en pretendiente frustrado se convierte el letrado Tomás Rueda, el licenciado Vidriera que se había propuesto, con tan solo once años, honrar a sus padres a través de sus estudios y que termina la novela marchándose a Flandes tras quejarse amargamente del sistema cortesano: «iOh Corte, que alargas las esperanzas de los atrevidos pretendientes, y acortas las de los virtuosos encogidos, sustentas abundantemente a los truhanes desvergonzados y matas de hambre a los discretos vergonzosos!» (Cervantes 2013, 301) (3) $^{13}$.

Dentro de estas coordenadas, la cuarta novela ejemplar, La española inglesa, nos lleva a una gran corte europea, contemporánea de Cervantes: el Londres de Elizabeth I. La acción conecta desde el comienzo con uno de los problemas que el escritor alcalaíno apuntará más tarde en el Persiles: «Clotaldo, un caballero inglés, capitán de una escuadra de navíos, llevó a Londres una niña de edad de siete años [...] aficionado, aunque cristianamente, a la hermosura de Isabel» $(2013,217)$. Clotaldo rapta a la protagonista porque no puede resistirse a su hermosura, tal y como hacen los «hijos de grandes» en el Persiles, aunque su intención, según explica el narrador, no sea erótica ${ }^{14}$.

13. Como indica Marín Cepeda, el excéntrico personaje es requerido en la corte por un gran señor, probablemente por su potencial bufonesco, pero él rechaza la invitación respondiendo: «Yo no soy bueno para palacio, porque tengo vergüenza y no sé lisonjear» (Cervantes 2013, 281). Sin embargo, «una vez que el licenciado Vidriera se halla en la corte madrileña y en poder de sus facultades mentales, nadie busca ya, sin embargo, su compañía, ni le presta atención porque ya no entretiene, su saber ya no interesa. Ha perdido su naturaleza bufonesca, tan cara a las cortes de la época como voces de las verdades difíciles, y ya no sirve para entretener a los cortesanos. Por sus méritos, que ha logrado por su ingenio y virtud y no por medio de favores [...] no logrará ni oficio ni beneficio en la corte de Madrid y, muerto de hambre, decide marcharse para servir al monarca como soldado en los tercios de Flandes» (2016, 40-41).

14. Para Clamurro (2012, 99-121), sin embargo, la novela esconde que el robo de Clotaldo es un acto de pedofilia. 
A la acción reprobable del noble sin título, un personaje ficticio, Cervantes opone «la voluntad y sabiduría del conde de Leste, que con gran diligencia hizo buscar la niña para volvérsela a sus padres» $(2013,217)$. No podemos pasar por alto que este conde sí es un personaje histórico ${ }^{15}$-probablemente el conde de Essex-y es precisamente quien muestra un comportamiento acorde con su estado.

Isabela crece secretamente en casa de Clotaldo y de su esposa Catalina, criptocatólicos en la Inglaterra anglicana. Lo hace en una condición de sirvienta o «prisionera» $(2013,222-223)^{16}$ que, sin embargo, llega a parecerse en ciertos aspectos a una adopción, a juzgar por la educación que recibe: Catalina «noble, cristina y prudente señora, tomó tanto amor que, como si fuera su hija, la criaba, regalaba, e industriaba» $(2013,218-219)$, mientras que «Clotaldo tenía cuidado de traerle a casa secretamente españoles que hablasen con ella» (219). Ricaredo, el hijo de estos nobles, repitiendo el patrón paterno, queda prendado de la belleza de Isabela, al principio como «un modo de agradarse y complacerse de ver la sin igual belleza de Isabel [...], amándola como si fuera su hermana» $(2013,219)$; pero, cuando la muchacha crece, «aquella benevolencia primera y aquella complacencia se volvió en ardentísimos deseos de gozarla y de poseerla; no porque aspirase a esto por otros medios que por los de ser su esposo» $(2013,219)$. El comportamiento honrado de Ricaredo viene motivado por «la incomparable hermosura de Isabela» (2013, 219), pero también «porque la noble condición suya y la estimación en que a Isabela tenía no consentían que ningún mal pensamiento echase raíces en su alma» $(2013,219)$. Ahora bien, como veremos, esa «noble condición» no es sinónimo de una «condición de noble», en tanto que la nobleza, como en el caso del rapto de Clotaldo, no garantiza un comportamiento recto.

Ricaredo, enfermo de amor por Isabela, le propone un matrimonio a escondidas de sus padres «un día que Isabela entró a servirle» $(2013,220)$. Sorprendentemente, la muchacha no responde dentro de las coordenadas sentimentales, sino en términos que dejan clara la conciencia de su situación social:

\footnotetext{
-Después que quiso el rigor o la clemencia del cielo, que no sé a cuál destos estremos lo atribuya, quitarme a mis padres, señor Ricaredo, y darme a los vuestros, agradecida a las infinitas mercedes que me han hecho, determiné que jamás mi voluntad saliese de la suya; y así, sin ella tendría no por buena, sino por mala fortuna la inestimable merced que queréis hacerme. Si con su sabiduría fuere yo tan venturosa que os merezca, desde aquí os ofrezco la voluntad que ellos dieren; y, en tanto que esto se dilatare o no fuere, entretengan vuestros deseos saber que los míos serán eternos y limpios en desearos el bien que el cielo puede daros $(2013,221)$.
}

15. Lozano-Renieblas (2013) ha mostrado que Cervantes se refiere al duque de Essex, encargado de la expedición que saqueó Cádiz en 1596, y que no se confunde con el conde de Leicester, como ha creído tradicionalmente el cervantismo.

16. Así aparece hasta en cinco ocasiones agrupadas en poco espacio. 
Las palabras de Isabela (una prisionera española de catorce años que llegó con siete a Londres) constituyen un claro ejemplo del aprendizaje del código del servicio-merced y suponen una muestra del «incremento desmesurado de las relaciones de servicio, eslabón del sistema clientelar, [...] tanto en la Corte como en una sociedad que mimetizaba, incluso en sus microcélulas, las estructuras y forma de vida cortesanas» (Torres Corominas 2011, 88). Este mismo código regirá también, como es lógico, en el ámbito estricto de la corte cuando, una vez que Ricaredo haya convencido a sus padres para casarse con la española, la reina les reclame que lleven a Isabela a palacio, donde les afeará no haber solicitado licencia para su casamiento, "porque sin su voluntad y consentimiento entre los de ilustre sangre no se efetúa casamiento alguno» $(2013,222)$.

La conducta de la muchacha en un momento especialmente delicado -pues Clotaldo y Catalina temen que se descubra su criptocatolicismo- muestra que ha asimilado el comportamiento cortesano a la perfección: «Llena de humildad y cortesía, se fue a poner de hinojos ante la reina, y en lengua inglesa, le dijo: -Dé Vuestra Majestad las manos a esta su sierva, que, desde hoy más, se tendrá por señora, pues ha sido tan venturosa que ha llegado a ver la grandeza vuestra» $(2013,224)$. La gracia y el donaire de Isabela, un elemento exótico en la corte tanto por su hermosura como por su condición de extranjera, provocan que la reina la reclame como suya, como parte del botín de guerra $^{17}$, y que decida dilatar el casamiento e integrarla dentro de su servicio: «Y se la entregó a una gran señora, su camarera mayor, para que la enseñase el modo de vivir suyo» $(2013,226)$. Mientras tanto, requiere a Ricaredo que sirva a la corona como justificación para merecer a la muchacha y lo envía como capitán de un navío a una expedición marítima en el Atlántico. El encargo hecho al héroe masculino se inserta, de nuevo, en las coordenadas del código servicio-merced. Clotaldo argumenta que los «muchos y relevados servicios que yo y mis pasados tenemos hechos a esta corona alcanzarían de Vuestra Majestad otras mercedes más dificultosas que las desta licencia» $(2013,225)$, pero la soberana le replica aludiendo a la necesidad de un mérito individual: «No quiero que para esto le aprovechen vuestros servicios ni de sus pasados», y explica a Ricaredo que debe entender el mandato como una «merced que os hago, pues os doy ocasión en ella a que [...] sirviendo a vuestra reina [...] alcancéis el mejor premio que, a mi parecer, vos mismo podéis acertar a desearos» $(2013,226)$. La decisión de la reina supone un agravio a Clotaldo, desautorizado públicamente, lo que hace que tanto él como sus acompañantes, tras la audiencia, salgan llenos de «despecho» $(2013,227)$.

Ricaredo vuelve triunfante como general de la expedición -cargo al que ha accedido por la (in)oportuna muerte del barón de Lansac-, con una nave portuguesa valorada en más de un millón de escudos, y trae consigo a los padres de Isabela, que se encontraban entre los españoles capturados por los

17. «Clotaldo, agravio me habéis hecho en tenerme este tesoro tantos años ha encubierto; mas él es tal, que os haya movido a codicia: obligado estáis a restituírmele, porque de derecho es mío» $(2013,225)$. 
turcos que el joven libera. El encuentro con la reina se produce de inmediato, porque «sin esperar otro acompañamiento que aquel de un innumerable vulgo que le seguía, se fue a palacio [...] con paso brioso» $(2013,236)$ y, vestido con sus ropajes militares ${ }^{18}$, se arrodilla ante la soberana para solicitar la entrega de Isabela como premio no solo por ese servicio, sino por los futuros:

Que con una joya sola que me dé quedaré en deuda de otras diez naves; la cual joya ya Vuestra majestad me la tiene prometida, que es a mi buena Isabela. Con ella quedaré rico y premiado, no sólo deste servicio, cual él se sea, que a Vuestra Majestad he hecho, sino de otros muchos que pienso hacer $(2013,236)$.

La respuesta de la reina debe leerse de nuevo en términos del código del servicio-merced, en los que se presenta como una monarca que tiene la potestad única y absoluta para premiar a sus súbditos ${ }^{19}$ :

Aunque os parezca que no hago mucho en volveros lo que es vuestro, yo sé que os hago mucha merced en ello [...]. Isabela es vuestra [...]; cuando quisiéredes podéis tomar su entera posesión, y creo será con su gusto, porque es discreta y sabrá ponderar la amistad que le hacéis, que no la quiero llamar merced, sino amistad, porque me quiero alzar con el nombre de que yo sola puedo hacerle mercedes $(2013,237)$.

La actitud física de Ricaredo muestra agradecimiento por haber obtenido el favor de su señora: «Besole las manos Ricaredo por las muchas mercedes que le hacía» $(2013,237)$. Por otro lado, pese a las palabras de la reina, cuando esta se marcha, y ante una broma de Tansi -otra de las damas de su séquito- Isabela sigue verbalizando su relación con Ricaredo dentro de las mismas coordenadas: «Señor Ricaredo, pues he de ser vuestra, a vos está tomar de mí toda la satisfación que quisiéredes para recompensaros de las alabanzas que me habéis dado y de las mercedes que pensáis hacerme» $(2013,237)$.

18. La vestimenta de Ricaredo ha llamado la atención de la crítica por su simbología y androginia: «Venía armado de peto, espaldar, gola y brazaletes y escarcelas, con unas armas milanesas de once vistas, grabadas y doradas, parecía en estremo bien a cuantos le miraban; no le cubría la cabeza morrión alguno, sino un sombrero de gran falda, de color leonado con mucha diversidad de plumas terciadas a la valona; la espada, ancha; los tiros, ricos; las calzas, a la esguízara. Con este adorno y con el paso brioso que llevaba, algunos hubo que le compararon a Marte, dios de las batallas, y otros, llevados de la hermosura de su rostro, dicen que le compararon a Venus, que, para hacer alguna burla a Marte, de aquel modo se había disfrazado» (2013, 235-236). Para Martínez Góngora, por ejemplo, es una «referencia a la pérdida de virilidad de Ricaredo [que] sugiere la ansiedad que provoca en el cortesano la necesidad de demostrar públicamente su masculinidad en el caso de hallarse sometido al control político de una mujer» $(2000,36)$.

19. Al respecto de este pasaje, Montcher $(2011,624)$ entiende que la reina categoriza como «amistad»su propio comportamiento con Isabela, y no el de Ricaredo. Trujillo $(2016,119)$ ve implicaciones de entendimiento político en la alusión de la monarca a la capacidad de la protagonista para «ponderar la amistad». 
Ricaredo vuelve al día siguiente, tal y como le manda la reina, para relatar por extenso su expedición y presentarle a los padres de la española. La soberana prepara esta recepción para premiarle por su éxito desde el comienzo, otorgándole distinciones públicas. En primer lugar, le «quiso lisonjear y favorecer con tener junto a sí a Isabela, vestida con aquel mismo vestido que llevó la primera vez» $(2013,238)$; después, le hace sentar en una «silla rasa» (es decir, un taburete) a su lado. Este último gesto tiene unas implicaciones sociales importantes, en tanto que supone una merced de primer orden. En el resto de la novela, tanto Isabela como Ricaredo se arrodillan siempre delante de la reina para dirigirse a ella, y así se mantienen a no ser que la soberana ordene expresamente lo contrario ${ }^{20}$. Este comportamiento ceremonial era habitual, incluso entre los nobles de más alto estado, en la etiqueta borgoñona ${ }^{21}$, mientras que lo contrario era una distinción notable, especialmente si se efectuaba de forma singular ${ }^{22}$. Así, el narrador señala expresamente que la actitud de la reina resulta extraordinaria: «No consintió la reina que Ricaredo estuviese de rodillas ante ella; antes le hizo levantar y sentar en una silla rasa, que para sólo esto allí puesta tenía, inusitada merced para la altiva condición de la reina» $(2013,239)$. La acción de la soberana, de hecho, suscita comentarios en la corte, de los que el narrador recoge tres. El primero subraya el mérito de Ricaredo frente a la merced de la reina: «Ricaredo no se sienta hoy sobre la silla que le han dado, sino sobre la pimienta que él trujo» (2013, 239); el segundo incide precisamente en la relación entre servicio y merced: «Ahora se verifica lo que comúnmente se dice, que dádivas quebrantan peñas, pues las que ha traído Ricaredo han ablandado el duro corazón de nuestra reina» $(2013,239)$. El tercero, en cambio, tiene una connotación negativa: «Ahora que está tan bien ensillado, más de dos se atreverán a correrle» (2013, 239), lo que da pie al narrador a subrayar la presencia de las envidias cortesanas, provocadas precisamente por el código del servicio-merced:

\footnotetext{
En efeto, de aquella nueva honra que la reina hizo a Ricaredo tomó ocasión la envidia para nacer en muchos pechos de aquéllos que mirándole estaban; porque no hay merced que el príncipe haga a su privado que no sea una lanza que atraviesa el corazón del envidioso $(2013,239)$.
}

La llegada de los padres de Isabela supone la inclusión de unos personajes que son no solo extranjeros, sino también ajenos al mundo de la nobleza y,

20. «Haciendo levantar a Isabela, le dijo» (225); «Levantaos, Ricaredo» en dos ocasiones (2013, 226, 236)

21. Véase al respecto Noel (2004, 151-152).

22. Pedro de Salazar y Mendoza, en su Origen de las dignidades seglares de Castilla y León [...] con un resumen de las mercedes que su majestad ha hecho, indica, entre otros casos, que el emperador Carlos hizo sentar y cubrirse la cabeza a Francisco de Borja dentro de su cámara, pero el jesuita no aceptó «el favor de sentarse y cubrirse, eligiendo estar de rodillas entre tanto que duró la visita» (1657, 58-59); o que Felipe III «mandó sentar en silla rasa, dentro de su cámara, a Juan Francisco Aldobrandino, sobrino del papa» y que «en la capilla mayor de la Iglesia Catedral de Burgos el duque de Lerma $[\ldots]$ se sentó junto a la cortina, separado del banco de los demás grandes» $(1657,59)$. 
por tanto, ajenos asimismo a los usos sociales de la misma. Su inferioridad social se pondrá de manifiesto cuando, ya en España, escriban a los padres de Ricaredo - que los habían acogido en casa, pero que eran también los captores de su hija- y les llamen «señores» (2013, 253). Ellos constituyen una perspectiva diferente, una visión externa del mundo de la corte, tal y como muestra su reacción ante la recepción en palacio: «Los padres de Isabela quedaron admirados y suspensos de ver tanta grandeza y bizarría junta» (2013, 238). En este contexto público, de forma planificada por Ricaredo, que ha decidido esconder la identidad de Isabela, se produce la anagnórisis, según los cánones clásicos que incluían una prueba física. Lo significativo de la escena, no obstante, es el comportamiento de los españoles, especialmente el de la madre, ajeno a los «miramientos cortesanos» $(2013,240)^{23}$.

El padre tampoco es capaz de contener las emociones, a pesar de que su actitud «prudente, dio muestras de su sentimiento no con otras palabras que con derramar lágrimas, que, sesgamente, su venerable rostro y barbas le bañaron» $(2013,241)$. La reina reprocha el comportamiento de Ricaredo y separa a Isabela de su madre, aunque cuando la mujer le pide disculpas por su «atrevimiento», explicando «que no es mucho perder los sentidos con la alegría del hallazgo» $(2013,241)$, le da la razón. Como indica Elias (2017), la sociedad cortesana imponía el autocontrol de los afectos como una norma básica de decoro. El resto de personajes son muy conscientes de ello, pero, como señala Paul M. Johnson, tienen dificultades para contener sus emociones o, al menos, disimularlas, y en ocasiones son incapaces de hacerlo ${ }^{24}$. La propia reina queda sin habla y «suspensa» $(2013,224-225)$ al contemplar por primera vez la belleza de Isabela, aunque logra dominarse sin mostrar debilidad ante sus súbditos. En cambio, a Ricaredo e Isabela les resulta imposible controlar el llanto al despedirse. El joven, «queriéndola hablar no pudo porque se le puso un nudo en la garganta que le ató la lengua, y las lágrimas acudieron a los ojos, y él acudió a disimularlas lo más que le fue posible; pero [...]

23. «Todo esto preguntó Isabela a su madre, la cual, sin responderle palabra, desatentadamente y medio tropezando, se llegó a Isabela y, sin mirar a respeto, temores ni miramientos cortesanos, alzó la mano a la oreja derecha de Isabela, y descubrió un lunar negro que allí tenía, la cual señal acabó de certificar su sospecha. Y, viendo claramente ser Isabela su hija, abrazándose con ella, dio una gran voz, diciendo:

-¡Oh, hija de mi corazón! ¡Oh, prenda cara del alma mía!

$\mathrm{Y}$, sin poder pasar adelante, se cayó desmayada en los brazos de Isabela» (2013, 240-241).

24. "That such heartfelt, emotive exchanges take place in the royal court, moreover, stands in stark contrast to the idea prescribed, popularized, and often parodied in courtly literature that successful courtiers had to repress and dissimulate their true feelings. Although characters in the novella recognize and at times express shame or regret for transgressing this directive of decorum in front of the queen (including Ricaredo and Isabela's parents), the fact that they are explicitly condoned, accepted, and even praised for their emotional outbursts in this milieu is surely significant. By representing the court as a space where emotions such as love, desire, shame, sadness, and wonder circulate among characters of distinct genders, nationalities, and socio-economic profiles, Cervantes forges affect as a medium of interpersonal exchange and potential resistance to dominant political structures and social expectations» (Johnson 2021). Sobre la disimulación como parte de la vida cortesana, véase Quondam (2013). 
no se le pudieron encubrir a los ojos de la reina» $(2013,227)$, que sin embargo, como ha apuntado Johnson (2021), comprende su llanto y le exhorta a no esconder sus emociones. Isabela, por su parte, «comenzó a derramar lágrimas, tan sin pensar lo que hacía y tan sesga y tan sin movimiento alguno, que no parecía sino que lloraba una estatua de alabastro» $(2013,227)$. Los «afectos $[\ldots]$ tan tiernos y enamorados» $(2013,227)$ llegan a conmover a gran parte del auditorio.

El mundo de la corte es presentado también como un territorio de peligro. El joven conde Arnesto, hijo de la camarera de la reina, queda prendado de la belleza de Isabela, de la misma manera que Clotaldo o que Ricaredo, y trata de cortejarla primero y, más tarde, de batirse en duelo con su competidor para impedir la boda el mismo día de su celebración. Su madre, desesperada, solicita a la reina que retrase el casamiento sin explicar el motivo, aludiendo a que «con esta merced sola que su Majestad le hiciese, se tendría por satisfecha y pagada de todas las mercedes que por sus servicios merecía y esperaba» $(2013,243)$. La novela justifica el comportamiento del personaje materno $^{25}$, que se había mostrado anteriormente como la confidente de la reina $(2013,224)$ y que el narrador había definido como una "gran señora» (2013, 226). La soberana concede el aplazamiento, pero mantiene su palabra de casar a Ricaredo con Isabela y se niega a enviar a la joven a España. Desesperada y temerosa por su hijo, la camarera decide asesinar a Isabela, que consigue salvar la vida pero pierde su belleza a causa del veneno. El acto es especialmente grave porque lo comete la persona a cuyo cuidado había quedado Isabela en la corte, y a quien la reina había encargado «que le enseñase el modo de vivir suyo» $(2013,226)$. La soberana propone a Ricaredo un castigo que satisfaga «en algo el deseo de venganza» $(2013,247) \mathrm{y}$, sin embargo, el joven noble le suplica que perdone a la camarera. Finalmente, decide desterrar al conde Arnesto y condenar a su madre «en que no sirviese más su oficio y en diez mil escudos de oro para Isabela» $(2013,249-250)$. Lo hace «sin acuerdo de letrados, y sin poner a su camarera en tela de juicio» $(2013,249)$, mostrando, como en los dramas de honor en los que aparecen monarcas, que su poder está por encima de cualquier órgano judicial.

El envenenamiento de Isabela desencadena los hechos posteriores: Clotaldo y Catalina entienden que, habiendo perdido su hermosura, Ricaredo no querrá casarse con ella, retoman el concierto de su hijo con una noble y rica escocesa y deciden enviar a la española y a sus padres de vuelta a su patria. Piden para ello licencia a la reina, que la concede. El héroe masculino propone a su enamorada un casamiento en secreto, que se efectúa de palabra, y mientras que Isabela va a España, dilata el casamiento con la escocesa con la excusa de que, como católico, debe viajar a Roma para asegurar su conciencia. Tras notables peripecias que incluyen un cautiverio, llega a España el

25. «Con todo eso, como madre, a quien es natural desear y procurar el bien de sus hijos, prometió al suyo de hablar a la reina: no con esperanza de alcanzar della el imposible de romper su palabra, sino por no dejar de intentar, como en salir desahuciada, los últimos remedios» $(2013,243)$. 
mismo día que se cumple el plazo de dos años dado a Isabela, quien ha recuperado la belleza y que, creyéndolo muerto, está a punto de ingresar en un convento sevillano.

En el encuentro final entre los dos protagonistas llama la atención la aparente frialdad de Isabela ${ }^{26}$, que D'Onofrio justifica de la siguiente forma: «Es entonces cuando Cervantes matiza con sutileza la interioridad de su personaje femenino, dando indicios de que es fuerte en la adversidad antes que insensible» $(2013,66)$. La joven ve a Ricaredo delante de una numerosa comitiva que ha ido a acompañarla para efectuar su profesión de fe, en la que están presentes también altas dignidades de la sociedad eclesiástica. Por ello, el racional discurso de Isabela puede analizarse además desde el control de los afectos que deben regir los actos públicos, según ha aprendido en la sociedad cortesana inglesa - primero en casa de la noble Catalina y más tarde en el palacio de la reina- y que sería un signo de su madurez social.

De ser así, estamos ante lo poco que le queda a Isabela de su pertenencia a la corte. En una inversión del comienzo de la novela, la joven invita a su esposo a casa de sus padres y el matrimonio se queda a vivir en Sevilla, «en las casas que alquilaron frontero de Santa Paula, que después las compraron de los herederos de un hidalgo burgalés que se llamaba Hernando de Cifuentes» $(2013$, 263). Como indica Carroll B. Johnson, Ricaredo renuncia a su nobleza y se incorpora a una familia que carece de linaje: los padres de Isabela no tienen ni siquiera un nombre propio, de manera que «la burguesía desplaza a la aristocracia» $(1989,523)$. En Sevilla los protagonistas no dependen ya de las mercedes de un monarca, porque, a pesar de que al despedirse de la reina, Isabela le agradece sus dádivas «con tales razones [...] que de nuevo dejó obligada a la reina para hacerle siempre mercedes» $(2013,251)$, la soberana nunca contesta a la carta que la joven le envía desde España. Su supervivencia económica no depende ya de un premio, sino que probablemente lo hace de las ganancias del oficio de mercader, ejercido por el padre de Isabela, cuyos frutos fecundos llegarían a sustituir la falta de descendencia según Carroll Johnson $(1989,524)$.

Como conclusión, más allá de las repercusiones sobre la identidad nacional de los protagonistas - Ricaredo acaba renunciando a su patria por la de Isabela-, la elección de Sevilla frente a Londres cabe interpretarse en el marco de un rechazo al mundo cortesano en favor de la libertad, en línea con gran parte de la literatura cervantina (Rey Hazas 2005, 224-228). La ciudad del Guadalquivir, bien conocida por el escritor alcalaíno, es la urbe que más aparece y más se menciona en su obra (Rey Hazas 2009, 199, n. 13), el lugar en el que se estableció siempre que pudo, movido probablemente por la liber-

26. «Vos, sin duda, señor mío, sois aquel que sólo podrá impedir mi cristiana determinación. Vos, señor, sois sin duda la mitad de mi alma, pues sois mi verdadero esposo; estampado os tengo en mi memoria y guardado en mi alma. Las nuevas que de vuestra muerte me escribió mi señora, y vuestra madre, ya que no me quitaron la vida, me hicieron escoger la de la religión, que en este punto quería entrar a vivir en ella. Mas, pues Dios con tan justo impedimento muestra querer otra cosa, ni podemos ni conviene que por mi parte se impida» $(2013,257)$. 
tad de la que allí podía gozar $(2009,190)$. Frente a los peligros de la vida áulica, sobre los que Cervantes había advertido ya en 1588, en el soneto preliminar de la Filosofía cortesana de Alonso de Barros ${ }^{27}$, Ricaredo e Isabela escogen la vida burguesa, fundada en el comercio de la puerta de las Indias. La fortuna de la pareja protagonista deja de estar sometida a las relaciones entre súbdita y señor y ya no depende de imposiciones -ni de las de los padres de Ricaredo ni de las de la reina de Inglaterra-. Cesan así los trabajos propios de la bizantina, generados en la novela fundamentalmente por el mundo de la corte. De esta manera, el otro componente del género, el amor, no se desarrolla ya como una merced otorgada, en las coordenadas establecidas por el sistema cortesano: no está sujeto al servicio a la corona ni depende tampoco de licencias reales, sino que puede conformarse por fin como un matrimonio igualitario, como última liberación de un cautiverio que había afectado a ambos cónyuges ${ }^{28}$.

\section{BIBLIOGRAFÍA CITADA}

Alvar Ezquerra, Alfredo. 2004. Cervantes. Genio y libertad. Madrid: Temas de Hoy.

Alvar Ezquerra, Alfredo. 2014. Un maestro en tiempos de Felipe II: Juan López de Hoyos y la enseñanza humanista del siglo XVI. Madrid: La Esfera de los Libros.

Barros, Alonso de. 2019 [1588]. Filosofía cortesana, ed. Ernesto Lucero. Madrid: Polifemo (Biblioteca Áulica 1).

Canavaggio, Jean. 1981. «La dimensión autobiográfica del Viaje del Parnaso». Cervantes: Bulletin of the Cervantes Society of America I, 1-2: 29-41.

Canavaggio, Jean. 1997. «Aproximación al Proceso Ezpeleta». Cervantes: Bulletin of the Cervantes Society of America XVII, 1: 25-45.

Canavaggio, Jean. 2005. Cervantes. São Paulo: Editora 34.

Cervantes Saavedra, Miguel de. 2013. Novelas ejemplares, ed. Jorge García López. Madrid - Barcelona: Real Academia Española - Galaxia Gutenberg/Círculo de Lectores.

Cervantes Saavedra, Miguel de. 2015. Don Quijote de la Mancha, ed. coord. Francisco Rico. Madrid - Barcelona: Real Academia Española - Espasa/Círculo de Lectores.

Cervantes Saavedra, Miguel de. 2016. Viaje del Parnaso y poesías sueltas, eds. José Montero Reguera y Fernando Romo Feito. Madrid - Barcelona: Real Academia Española - Espasa/Círculo de Lectores.

Cervantes Saavedra, Miguel de. 2017. Los trabajos de Persiles y Sigismunda, ed. Laura Fernández. Madrid - Barcelona: Real Academia Española - Espasa/Círculo de Lectores.

Clamurro, William H. 2012. «The sins of the father. La española inglesa». En Beneath the Fiction: The Contrary Words of Cervantes's Novelas Ejemplares, 99-121. Nueva York: Peter Lang.

Crespo, Mario. 2002. «Cervantes y la corte: lecturas biográficas, patrocinio e interpretaciones políticas». Studia Storica 24: 255-295.

27. «El que navega por el golfo insano / del mar de pretensiones, verá al punto / del cortesano laberinto el hilo» $(2019,132)$.

28. Sobre La española inglesa como una novela de cautiverio doble, véase Santos de la Morena (en prensa). 
D’Onofrio, Julia. 2013. «Efectismo, eutrapelia y el poder de la fícción. La española inglesa y los modos amables de la ejemplaridad cervantina». En Don Quijote en Azul 5. Actas selectas de V Jornadas Internacionales Cervantinas, coords. Julia D'Onofrio y Clea Gerber, 51-70. Azul: Editorial Azul.

Elias, Norbert. 2017. La sociedad cortesana. México: FCE (edición electrónica, sin paginar). García López, Jorge. 2015. Cervantes. La figura en el tapiz. Barcelona: Pasado y Presente. García Reidy, Alejandro. 2013. Las musas rameras. Oficio dramático y conciencia profesional en Lope de Vega. Madrid - Fráncfort: Iberoamericana - Vervuert.

Gómez, Jesús. 2013. El modelo teatral del último Lope de Vega (1621-1635). Valladolid - Olmedo: Universidad de Valladolid - Ayuntamiento de Olmedo.

Gracia, Jordi. 2016. Miguel de Cervantes. La conquista de la ironía. Madrid: Taurus.

Johnson, Carroll B. 1989. "Catolicismo, familia y fecundidad: el caso de La española inglesa». En Actas del IX Congreso de la Asociación Internacional de Hispanistas, coord. Sebastian Neumeister, vol. 1, 519-524. Fráncfort: Vervuert.

Johnson, Paul M. 2021. Affective Geographies: Cervantes, Emotion, and the Literary Mediterranean. Toronto: Toronto University Press (libro electrónico, edición sin paginar).

López de Hoyos, Juan. ed. 1569. Historia y relación verdadera de la enfermedad, felicísimo tránsito y sumptuosas exequias fúnebres de la Serenísima Reina de España Doña Isabel de Valois. Madrid: Pierres Cosin.

Lozano-Renieblas, Isabel. 2013. «Pesquisa sobre el conde de Leste». Hesperia. Anuario de filología hispánica XVI, 2: 43-57.

Lucía Megías, José Manuel. 2016a. La juventud de Cervantes. Una vida en construcción: retazos de una biografía en el Siglo de Oro. Parte I. Madrid: EDAF (libro electrónico, edición sin paginar).

Lucía Megías, José Manuel. 2016b. La madurez de Cervantes. Una vida en la corte: retazos de una biografía en el Siglo de Oro. Parte II. Madrid: EDAF (libro electrónico, edición sin paginar).

Marín Cepeda, Patricia. 2007. «Acerca del contexto histórico de Miguel de Cervantes». Revista de Estudios Cervantinos 1: 1-19.

Marín Cepeda, Patricia. 2015. Cervantes y la corte de Felipe II. Escritores en el entorno de Ascanio Colonna (1560-1608). Madrid: Polifemo.

Marín Cepeda, Patricia. 2016. "No soy bueno para palacio": Cervantes y el mecenazgo literario». En Cervantes: los viajes y los días, ed. Pedro Ruiz Pérez, 31-42. Madrid: SIAL (Prosa Barroca).

Martínez-Góngora, Mar. 2000. «Un unicornio en la corte de una reina virgen. Ginecocracia $\mathrm{y}$ ansiedades masculinas en La española inglesa». Cervantes: Bulletin of the Cervantes Society of America XX, 1: 27-46.

Martínez Millán, José. 1994. «Los estudios sobre la corte. Interpretación de la corte de Felipe II». En La corte de Felipe II, dir. José Martínez Millán, 13-35. Madrid: Alianza Editorial.

Montcher, Fabien. 2011. «La española inglesa de Cervantes en su contexto historiográfico». En Visiones y revisiones cervantinas: actas selectas del VII Congreso Internacional de la Asociación de Cervantistas, coord. Christoph Strosetzki, 617-628. Alcalá de Henares: Centro de Estudios Cervantinos.

Montero, Juan y Antonio Sánchez Jiménez, eds. 2017. Carrera literaria y representación autorial en la literatura del Siglo de Oro. eHumanista. Journal of Iberian Studies 38: $1-237$.

Montero Reguera, José. 1992. «Epistolario de Miguel de Cervantes». Castilla. Estudios de Literatura 17: 81-101. 
Noel, Charles C. 2004. «La etiqueta borgoñona en la corte de España (1547-1800)». Manuscrits 22: 139-158.

Piqueras Flores, Manuel y Elena Trapanese. 2020. «Un lugar para la sociabilidad literaria: Sor Juana, Salas Barbadillo y otras casas de placer». En Ámbitos artísticos y literarios de sociabilidad en los Siglos de Oro, eds. Alejandra Ulla y Elena Martínez Carro, 239258. Kassel: Reichenberger.

Quondam, Amedeo. 2013. El discurso cortesano, ed. y trad. Eduardo Torres Corominas. Madrid: Polifemo.

Redondo, Agustín. 1998. «Fiestas burlescas en el palacio ducal: el episodio de Altisidora». En Actas del Tercer Congreso Internacional de la Asociación de Cervantistas, ed. Antonio Bernat Vistarini, 49-62. Mallorca: Universitat de les Illes Balears.

Rey Hazas, Antonio. 2005. Poética de la libertad y otras claves cervantinas. Madrid: Eneida.

Rey Hazas, Antonio. 2009. «Andalucía en las Novelas ejemplares de Cervantes: una reflexión sobre el espacio novelesco cervantino». Anales Cervantinos XLI: 189-215. https://doi.org/10.3989/anacervantinos.2009.009

Rey Hazas, Antonio. 2013. «Novelas cortas y episodios en el Quijote de 1605. La venta y la corte en la reestructuración final del texto». En Ficciones en la ficción: poéticas de la narración inserta (siglos XV-XVII), ed. Valentín Núñez Rivera, 181-214. Bellaterra: Universidad Autónoma de Barcelona.

Ruiz, Pedro. 2018. La rúbrica del poeta. Valladolid: Universidad de Valladolid.

Ruiz, Pedro, ed. 2019a. Autor en construcción. Sujeto e institución literaria en la modernidad hispánica (siglos XVI-XIX). Zaragoza: Universidad de Zaragoza.

Ruiz, Pedro. 2019b. «El sujeto literario a partir de Cervantes. Laberintos, vuelos, espejos». En Autor en construcción. Sujeto e institución literaria en la modernidad hispánica (siglos XVI-XIX), ed. Pedro Ruiz, 119-152. Zaragoza: Universidad de Zaragoza.

Sáez, Adrián J., ed. 2016. Miguel de Cervantes Saavedra. Poesías. Madrid: Cátedra.

Salazar y Mendoza, Pedro. 1657. Origen de las dignidades seglares de Castilla y León. Madrid: Imprenta Real.

Sánchez Jiménez, Antonio. 2018. Lope: el verso y la vida. Madrid: Cátedra.

Santos de la Morena, Blanca. En prensa. «La española inglesa y el inglés español, una doble novela de cautiverio». Revista de literatura.

Sliwa, Krzysztof. 2005. Vida de Miguel de Cervantes Saavedra. Kassel: Reichenberger.

Teijeiro Fuentes, Miguel Ángel. 2013. «Cervantes y los mecenas: denle una segunda oportunidad y escribirá El Quijote». Anales Cervantinos XLV: 9-44. https://doi. org/10.3989/anacervantinos.2013.001

Tietz, Manfred y Marcella Trambaioli, coords. 2011. El autor en el Siglo de Oro: su estatus intelectual y social. Vigo: Academia del Hispanismo.

Torres Corominas, Eduardo. 2011. «"Un oficio real”: el Lazarillo en la escena de la corte». Criticón 113: 85-118.

Torres Corominas, Eduardo, ed. 2013. Amadeo Quondam, El discurso cortesano. Madrid: Polifemo.

Trujillo, José Ramón. 2016. «Lenguas, comunicación interlingüística y verosimilitud en la novela corta cervantina». En Nuevos enfoques sobre la novela corta barroca, coords. Mechthild Albert, Ulrike Becker, Rafael Bonilla Cerezo y Angela Fabris, 111-130. Fráncfort del Meno: Peter Lang. 
